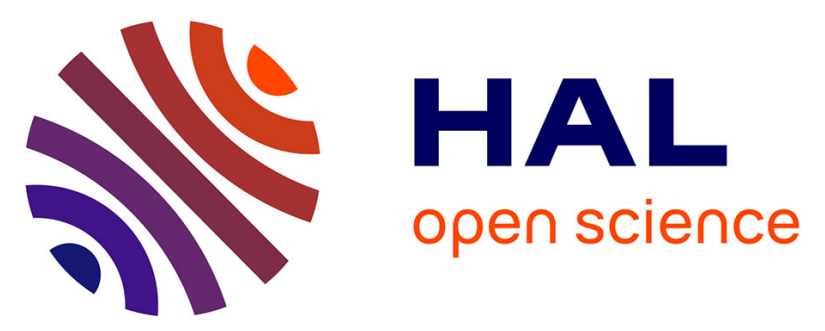

\title{
Broad-spectrum resistance loci for three quantitatively inherited diseases in two winter wheat populations
}

Thomas Miedaner, Peter Risser, Sophie Paillard, Thorsten Schnurbusch, Beat

Keller, Lorenz Hartl, Josef Holzapfel, Viktor Korzun, Erhard Ebmeyer, Friedrich H Utz

\section{To cite this version:}

Thomas Miedaner, Peter Risser, Sophie Paillard, Thorsten Schnurbusch, Beat Keller, et al.. Broadspectrum resistance loci for three quantitatively inherited diseases in two winter wheat populations. Molecular Breeding, 2011, 29 (3), pp.731-742. 10.1007/s11032-011-9586-6 . hal-02959014

\section{HAL Id: hal-02959014 https://hal.inrae.fr/hal-02959014}

Submitted on 6 Oct 2020

HAL is a multi-disciplinary open access archive for the deposit and dissemination of scientific research documents, whether they are published or not. The documents may come from teaching and research institutions in France or abroad, or from public or private research centers.
L'archive ouverte pluridisciplinaire HAL, est destinée au dépôt et à la diffusion de documents scientifiques de niveau recherche, publiés ou non, émanant des établissements d'enseignement et de recherche français ou étrangers, des laboratoires publics ou privés. 


\title{
Broad-spectrum resistance loci for three quantitatively inherited diseases in two winter wheat populations
}

\author{
Thomas Miedaner $\cdot$ Peter Risser $\cdot$ Sophie Paillard $\cdot$ Thorsten Schnurbusch \\ Beat Keller • Lorenz Hartl · Josef Holzapfel • Viktor Korzun • \\ Erhard Ebmeyer $\cdot$ H. Friedrich Utz
}

Received: 19 January 2011/Accepted: 30 April 2011

(C) Springer Science+Business Media B.V. 2011

\begin{abstract}
Septoria tritici blotch (STB), caused by S. tritici, Stagonospora glume blotch (SGB), caused by $S$. nodorum, and Fusarium head blight (FHB), caused by $F$. graminearum and $F$. culmorum, are the
\end{abstract}

Electronic supplementary material The online version of this article (doi:10.1007/s11032-011-9586-6) contains supplementary material, which is available to authorized users.

T. Miedaner $(\varangle) \cdot$ P. Risser

State Plant Breeding Institute, Universität Hohenheim, Fruwirthstr. 21, 70599 Stuttgart, Germany

e-mail: miedaner@uni-hohenheim.de

Present Address:

P. Risser

KURATORIUM für Versuchswesen und Beratung im

Zuckerrübenanbau, Marktbreiter Straße 74, 97199

Ochsenfurt, Germany

S. Paillard · T. Schnurbusch · B. Keller

Institute of Plant Biology, University of Zurich,

Zollikerstrasse 107, 8008 Zurich, Switzerland

Present Address:

S. Paillard

UMR 118-Amélioration des Plantes et Biotechnologies

Végétales, Plant Genetics and Biotechnologies, INRA-

Agrocampus-Ouest, Université Rennes 1, Domaine de la

Motte, BP 35327, 35653 Le Rheu Cedex, France

Present Address:

T. Schnurbusch

Leibniz-Institut für Pflanzengenetik und

Kulturpflanzenforschung (IPK), Corrensstr. 3, 06466

Gatersleben, Germany most important diseases of wheat (Triticum aestivum L.) in temperate growing areas. The main goals of this study were to detect (1) new quantitative trait loci (QTL) for STB resistance in two adapted European biparental populations (Arina/Forno, History/Rubens) and (2) QTL regions for broad-spectrum resistance (BSR) to the above-mentioned diseases during the adult-plant stage in the field. The three resistances

\author{
L. Hartl · J. Holzapfel \\ Bayerische Landesanstalt für Landwirtschaft, Institut für \\ Pflanzenbau und Pflanzenzüchtung, AG \\ Züchtungsforschung Weizen und Hafer, Am Gereuth 8, \\ 85354 Freising, Germany \\ Present Address: \\ J. Holzapfel \\ Saatzucht Josef Breun GdbR, Amselweg 1, 91074 \\ Herzogenaurach, Germany \\ H. F. Utz \\ Institute of Plant Breeding, Seed Science, and Population \\ Genetics, Universität Hohenheim, Fruwirthstr. 21, 70599 \\ Stuttgart, Germany \\ V. Korzun · E. Ebmeyer \\ KWS LOCHOW GMBH, 29303 Bergen, Germany
}


were phenotyped across 4-7 field environments and phenotypic data revealed significant $(P<0.01)$ genotypic differentiation in all cases. Entry-mean heritabilities $\left(h^{2}\right)$ ranged from 0.73 to 0.93 . For STB resistance, correlations between disease ratings and heading date were significant $(P<0.01)$, but moderate $(r=-0.23$ to -0.30$)$ in both populations. Correlations between STB and plant height were higher in Arina/Forno $(r=-0.45)$ and History/ Rubens $(r=-0.55)$, the latter population segregating at the Rht-Dl locus. During the initial QTL analysis, 5 QTL were detected for STB resistance in each of the populations, amounting to an explained genotypic variance of $45-63 \%$, thus, showing the same ranges as FHB and SGB resistances in Arina/ Forno and FHB resistance in History/Rubens. In total, 7 BSR QTL were found in the meta-analysis with the raw data, including the QTL on chromosome 4D at the $R h t-D 1$ locus. A BSR QTL for all three diseases was not found but several BSR QTL for combinations with two diseases were detected. Combining the BSR QTL detected in the present breeding material by applying marker-assisted selection seems a promising approach.

Keywords Adult-plant resistance $\cdot$ Broad spectrum resistance · Fusarium head blight · Meta-analysis · Mycosphaerella graminicola · Phaeosphaeria nodorum · QTL · Septoria tritici blotch · Septoria glume blotch · Triticum aestivum - Wheat

\section{Introduction}

Wheat (T. aestivum L.) is one of the most important food crops worldwide, covering more land area than any other crop (FAOSTAT 2010). In Germany, arable land comprises about 12 million hectares including 3.2 million hectares of wheat. In comparison to other wheat-growing regions worldwide with an average yield of 1-3 t/hectare, Germany is one of the highest yielding areas with an average yield of 7-8 t/hectare (FAOSTAT 2010), with winter wheat being predominant. Several fungal diseases restrict maximum grain yield, among which Septoria tritici blotch (STB), caused by $S$. tritici (teleomorph $M$. graminicola), Stagonospora glume blotch (SGB), caused by S. nodorum (teleomorph P. nodorum), and Fusarium head blight (FHB), caused by
$F$. graminearum (teleomorph G. zeae) and F. culmorum, are the most important fungal pathogens. Each of them can cause considerable yield losses. FHB additionally affects grain quality and leads to mycotoxin contamination. Cultivation of resistant varieties is the most environmentally friendly and cost-effective strategy for controlling these diseases.

The main challenge in European wheat breeding is to combine maximum grain yield with good baking quality and acceptable levels of resistance to the most important pathogens. Resistances to STB, FHB, and SGB are of great relevance in wheat breeding; they are quantitatively inherited and controlled by multiple genes (Schnurbusch et al. 2003; Paillard et al. 2004; Semagn et al. 2007; Uphaus et al. 2007; Holzapfel et al. 2008; Shankar et al. 2008; Bonin and Kolb 2009). Additionally, race-specific resistances are mediated by several $S t b$ resistance genes ( $c f$. Goodwin 2007). Analyses of quantitative trait loci (QTL) were previously carried out for resistance to FHB (Paillard et al. 2004) and SGB (Schnurbusch et al. 2003; Abeysekara et al. 2009) in the Swiss population Arina/Forno and for resistance to FHB in History/Rubens (Holzapfel et al. 2008). The resistance donor Arina was mapped independently in other studies for STB resistance (Chartrain et al. 2004) and FHB resistance (Draeger et al. 2007; Semagn et al. 2007). A recently published QTL analysis of quantitative STB resistance in two other European wheat populations (Florett/Biscay, Tuareg/ Biscay) revealed a high number of loci with two major QTL/population (Risser et al. 2011). Broadspectrum resistance (BSR) is restricted in our study to loci conferring resistance to multiple taxa of pathogens within one crop (Poland et al. 2009). BSR loci have previously been described in Arabidopsis, maize and rice (Cao et al. 1998; Wisser et al. 2005; Wisser 2006). In Arabidopsis even individual genes effective against groups of pathogens, e.g., NDR1, NPRl, esal, WRKY33, have been cloned ( $c f$. Poland et al. 2009). There is also evidence for the existence of BSR loci in wheat, including the detection of non-adapted germplasm with resistances to multiple diseases (Gurung et al. 2009) and clustering of resistance genes in distinct genomic regions such as on chromosomes 3BS (Sr2, Lr27, Yrns-B1, Rph7-homologue, FHB, SNG; $c f$. Miedaner et al. 2008) or 3DL (seedling STB, tan spot, Lr24, Sr24; Zwart et al. 2010). Another prominent example is the Lr34/Yrl8/ 
Pm38 locus in wheat which confers resistance to leaf rust, yellow (stripe) rust, powdery mildew, and barley yellow dwarf virus $(B d v 1)$. This locus represents a single gene (Krattinger et al. 2009) and is the only example in wheat where the actual gene causing BSR has been cloned.

Meta-QTL analysis identifies consensus QTL across studies which allows validation of results from individual studies and refining of QTL positions on the consensus map by statistical methods (Goffinet and Gerber 2000). In contrast to meta-QTL studies for disease resistance using data from the literature (Liu et al. 2009; Löffler et al. 2009), we searched for BSR QTL within two elite populations across different quantitative resistances by combining the original data from several experiments. The objectives were to (1) analyze the Arina/Forno and History/Rubens populations for quantitative STB resistance QTL for the first time and (2) identify chromosomal locations, positions, support intervals, and genetic effects of BSR-QTL by combining STB data with FHB (History/Rubens) and FHB and SGB data (Arina/Forno) from previous mapping studies by meta-QTL analysis.

\section{Materials and methods}

Initial population development

In previous studies, mapping populations of 240 and 103 recombinant inbred lines (RILs) were developed from a cross between Arina and Forno and between History and Rubens, respectively (Paillard et al. 2003; Schnurbusch et al. 2003; Holzapfel et al. 2008). Arina and Forno are Swiss cultivars; History and Rubens have been bred in Germany. Arina is quantitatively resistant to STB, FHB, and SGB, History to FHB and STB; Forno and Rubens are the susceptible parents with the latter including the dwarfing allele Rht-Dlb. For this study, 200 and 94 RILs were used from Arina/Forno and History/ Rubens, respectively.

Field trials, inoculation, and resistance evaluation

All populations were evaluated for all disease resistances in independent series of field experiments. RILs of Arina/Forno have previously been evaluated for FHB severity by spray inoculation in each of 6 environments (location-year combinations, Paillard et al. 2004) and for SGB severity by natural infections in 7 environments (Schnurbusch et al. 2003). RILs of History/Rubens were spray-inoculated for induction of FHB symptoms in 5 environments (Voss et al. 2008). All disease resistances were recorded by 3-5 visual ratings during epidemic development as the percentage of infected glume or leaf area, from $0 \%$, i.e., no visible lesions, up to $100 \%$. SGB and FHB in History/Rubens were rated on a plot basis, FHB in Arina/Forno on the basis of 10 randomly chosen ears from each plot.

In this study, RILs of Arina/Forno were for the first time evaluated for quantitative STB resistance in four locations (Hohenheim/Stuttgart, Oberer Lindenhof near Reutlingen, Freising near Munich, Wohlde near Celle) in 2009 and RILs of History/Rubens at each of three locations in 2008 and 2009 (Hohenheim, Oberer Lindenhof, Freising). The populations were grown together with 5 replicated entries of the parental lines in $\alpha$-designs with two replications at each trial. Each entry was sown in two 1 m rows with approximately 40-60 kernels/row.

Inoculation and resistance evaluation for STB severity has previously been described in detail (Risser et al. 2011). In brief, we used one or two pretested isolates of $S$. tritici that infected all four parents in a seedling test to $90-100 \%$ : isolates BAZ 6/1/04 and BAZ 8/8/04 for Arina/Forno and BAZ 8/8/ 04 for History/Rubens. With this procedure, we wanted to exclude the effect of race-specific $S t b$ resistance genes known to reside in Arina (Stb6, Stb15), Forno (Stb6), and Rubens (Stb6) and expressed in the seedling stage. We wanted to ensure that we detected quantitative adult-plant resistances only. Inoculum was produced at the Institute of Crop Science and Plant Breeding, Freising, and sprayed once with $5 \times 10^{6}$ spores $/ \mathrm{ml}$ by a tractor-mounted sprayer in the period between full appearance of flag leaf and mid flowering after late genotypes' flag leaves had been fully unrolled. Inoculation was done after rainfall and during cloudy weather conditions so that moisture was retained on the leaf surface for several hours. At Freising 2009, mist irrigation was used after inoculation to enhance infection frequency.

In all field trials STB, heading date, and plant height were evaluated. STB severity was visually scored plotwise as percentage coverage of flag leaves 
with lesions bearing pycnidia. Flag leaves were assessed three times at an interval of 4-7 days, starting from about 30 days after inoculation. The arithmetic mean of two scorings, representing middle and end of disease development, was used in the following analyses. Unfortunately, inoculation at Wohlde did not lead to any scorable STB. Heading date was scored as days after 1st January when $50 \%$ of spikes of a plot had emerged. Plant height was measured from the soil surface to the middle of the spike on the main tillers.

Phenotypic data analyses

Analyses of phenotypic data were based on singleplot values. Estimation of variance components was done using the programme package PLABSTAT (Utz 2001). Residuals of STB mapping populations did not follow a normal distribution. Logit and arcsin transformations were applied, but did not improve the normality of the data. Therefore, untransformed data were used for analysis of variance (ANOVA) and QTL analysis. Lattice-adjusted means were calculated for genotypes in each environment and used for ANOVA. Analysis across environments was performed using a general linear model with genotype and environment effects, considering genotype as random. Entry-mean heritability $\left(h^{2}\right)$ was calculated by PLABSTAT as the ratio of genotypic to phenotypic variance (Knapp et al. 1985):

$h^{2}=\frac{\sigma_{g}^{2}}{\sigma_{g}^{2}+\frac{\sigma_{g e}^{2}}{E}+\frac{\sigma^{2}}{E R}}$.

where $\sigma_{g}^{2}$ denotes the genotypic variance, $\sigma_{g e}^{2}$ the genotype $\times$ environment interaction variance, and $\sigma^{2}$ the error variance. $E$ and $R$ are the numbers of environments and replications/environment, respectively.

\section{Genetic maps}

A detailed genetic map of Arina/Forno was published by Paillard et al. (2003) with 380 marker loci spanning a total of 3,086 cM. The map of History/Rubens originally included 394 loci across $2,187 \mathrm{cM}$ (Holzapfel et al. 2008). For this study, additional 97 polymorphic Diversity Arrays Technology (DArT) loci were included in the latter map (Risser 2010).
Abbreviations of DArT markers were used as provided by Triticarte (Triticarte P/L, Yarralumla, Australia, http://www.triticarte.com.au) with wPt and $\mathrm{tPt}$ referring to markers documented in the wheat and triticale map, respectively. Amplified fragment length polymorphism (AFLP) loci were designated according to the standard list provided by the manufacturer (KeyGene Inc., Wageningen, The Netherlands). For example, marker locus P6451-190 refers to a fragment of about 190 base pairs (bp) amplified with primer combination P64/M51 using Pst I/MseI restriction enzymes. All simple sequence repeat (SSR) loci mentioned are publicly available.

QTL analyses

QTL analyses were applied within History/Rubens and Arina/Forno across three diseases: FHB, SGB, and STB. Schnurbusch et al. (2003), Paillard et al. (2004), and Holzapfel et al. (2008) provided phenotypic raw data of SGB (percentage of the infected glume area/spike) and FHB (percentage of diseased spikelets). In order to compare QTL effects between different experiments, the area under the disease progress curve (AUDPC) was not used for SGB and FHB in Arina/Forno, but rather the arithmetic mean of two scorings.

Initial QTL analysis was performed using composite interval mapping (CIM) by a multiple regression procedure with the program PLABMQTL (Utz 2009). We applied a LOD threshold of 3.0 to declare the presence of a putative QTL according to the previous authors working with the same populations. The Bayesian Information Criterion (BIC) was used to select the final model from the initially detected putative QTL having a LOD above the critical threshold. The critical LOD threshold was determined empirically according to Churchill and Doerge (1994) using 1,000 permutation runs. The proportion of genotypic variance $\left(\sigma_{G}^{2}\right)$ explained by the model was calculated from the whole dataset $\left(\hat{p}_{D S}\right)$ as $\hat{p}_{D S}=\hat{R}_{\text {adj }}^{2} / \hat{h}^{2}$, where $\hat{R}_{\text {adj }}^{2}$ is the adjusted proportion of phenotypic variance explained by the model and $\hat{h}^{2}$ is the heritability of the trait (Schön et al. 2004). The proportion of $\sigma_{g}^{2}$ explained by individual QTL in the model $\left(\hat{p}_{\text {part }}\right)$ was calculated as $\hat{p}_{\text {part }}=\hat{R}_{\text {part }}^{2} / \hat{h}^{2}$ where $\hat{R}_{\text {part }}^{2}$ is the proportion of the phenotypic variance 
explained by individual QTL. Individual $\hat{p}_{\text {part }}$ values were normalized according to Zhu et al. (2004) to sum up to $\hat{p}_{D S}$. The $95 \%$ confidence interval (CI) of the detected QTL was calculated after Darvasi and Soller (1997). Jiang and Zeng (1995) have proposed a multiple trait version of the CIM technique. This method is based on maximum likelihood, and requires special programs for analysis. We used PLABMQTL, written by the senior author (Utz 2009). If the correlation between residual effects of the traits is zero, the joint test statistic is approximately the sum of the test statistics for the single traits $\mathrm{LR}_{\mathrm{j}} \sim \mathrm{LR}_{\mathrm{S} 1}+$ $\mathrm{LR}_{\mathrm{S} 2}$ (van der Werf 2000). Equal QTL-mapping procedures were applied for all three diseases to obtain comparable LOD curves and estimations of QTL effects. Meta-analysis was done by adding LOD scores of disease traits within each population. History/Rubens was analyzed for resistance to FHB and STB, Arina/Forno for resistance to FHB, SGB, and STB. According to the procedure described above, $\hat{p}_{\text {part }}$ was calculated as the part of genotypic variance explained by each individual BSR QTL. Critical LOD scores were determined within the program PLABMQTL by 1,000 permutation runs.

\section{Results}

QTL mapping for resistance to STB

Field trials revealed differentiation for STB rating between the parents and within the two mapping populations (Electronic Supplementary Material Table S1). Variance components for STB were highly significant $(P<0.01)$ for genotype and $\mathrm{G} \times \mathrm{E}$ interaction. History/Rubens population had a larger genotypic variance and only a slightly higher $\mathrm{G} \times \mathrm{E}$ interaction than Arina/Forno. Accordingly, entry-mean heritability was higher for the former population. Correlations between STB and heading date were negative and low for Arina/Forno and History/Rubens ( $r=-0.23$ and -0.30 , respectively) although significant $(P<0.01)$. Correlations between STB and plant height were considerably higher for Arina/Forno and History/Rubens $(r=-0.45$ and -0.55 , respectively).

Both mapping populations showed a continuous distribution of mean STB rating averaged across environments (Electronic Supplementary Material Figure S1). Parental lines were located at either end of the distribution.

For STB resistance, we detected 5 QTL in each of both populations located on 5 chromosomes in Arina/ Forno and four chromosomes in History/Rubens with LOD $>3$ in the combined analysis across environments (Table 1). Due to the small size of the latter population, only QTL 1 is significant according to the critical LOD score after permutations. Values of $\hat{p}_{\text {part }}$ ranged between 3.0 and 24.4, with four QTL exceeding $10 \%$. About half of the QTL show significant $(P<0.01)$ QTL $\times$ environment interaction.

Meta-analysis for broad-spectrum resistance QTL

Initial QTL analyses across all disease resistances in Arina/Forno revealed 7 and 3 QTL for FHB and SGB resistance, respectively, explaining together 52 and $42 \%$ of the genotypic variance (Electronic Supplementary Material Table S2). In History/Rubens, 6 QTL for FHB resistance were mapped, explaining $62 \%$ of $\hat{p}_{D S}$.

For meta-QTL analysis, LOD scores for STB, FHB, and SGB resistance in Arina/Forno and for STB and FHB resistance in History/Rubens were added to determine chromosomal localization, position, flanking markers, support interval (SI), and LOD scores of meta-QTL. Additionally, heading date and plant height in this study were used in meta-analysis. Using PLABMQTL, 7 QTL were detected showing significant $(P<0.01)$ additive effects across at least two resistance traits, located on chromosomes $3 \mathrm{~B}$, $4 \mathrm{~B}, 5 \mathrm{~B}$, and $6 \mathrm{D}$ in Arina/Forno, and on chromosomes 2B, 4D, and 7B in History/Rubens, and were declared as BSR QTL. Meta-LOD scores ranged from 6.1 to 22.7 and from 18.1 to 48.7 , respectively. Five out of seven BSR QTL were still significant at $P<0.01$ by their critical LOD thresholds after the permutation test.

The BSR QTL with the highest additive effects was on chromosome 4D in History/Rubens, closely linked to the dwarfing Rht-Dl locus (Table 2). The tall allele from History reduced disease severity by 9.8\% for STB and $6.3 \%$ for FHB. All resistance alleles at one BSR QTL were contributed by the same parent. In Arina/Forno, no BSR QTL was found to have a significant effect on all three disease 
Table 1 Chromosomal localization, flanking markers, LOD scores, distance to the next flanking marker (Dis.) and confidence interval $(\mathrm{CI})$ of QTL with LOD $\geq 3.0$ for resistance to $S$. tritici blotch (\% flag leaf area affected, means across environments); $N=$ population size

\begin{tabular}{|c|c|c|c|c|c|c|c|c|c|}
\hline \multirow[t]{2}{*}{ No. } & \multirow[t]{2}{*}{ Chromosome } & \multirow[t]{2}{*}{ Position (cM) } & \multicolumn{2}{|c|}{ Flanking marker ${ }^{\mathrm{a}}$} & \multirow[t]{2}{*}{$\mathrm{LOD}^{\mathrm{b}}$} & \multirow[t]{2}{*}{ Dis. (cM) } & \multirow{2}{*}{$\begin{array}{l}\mathrm{CI}^{\mathrm{c}} \\
(\mathrm{cM})\end{array}$} & \multirow[t]{2}{*}{$\hat{p}_{\text {part }}^{\mathrm{d}}$} & \multirow[t]{2}{*}{$\mathrm{QTL} \times \mathrm{E}^{\mathrm{e}}$} \\
\hline & & & Right & Left & & & & & \\
\hline \multicolumn{10}{|c|}{ Arina/Forno $(N=200)$} \\
\hline 1 & $2 \mathrm{~B}$ & 140 & Xpsr540 & Xcfd276 & 5.5 & 0 & $133-147$ & 9.6 & $* *$ \\
\hline 2 & $3 \mathrm{~B}$ & 112 & Xcfab2134 & Xgwm131 & 7.3 & 2 & $96-128$ & 14.2 & $* *$ \\
\hline 3 & $5 \mathrm{~B}$ & 44 & Xwmc473 & Xpsr574 & 4.7 & 0 & $37-51$ & 6.7 & \\
\hline 4 & $6 \mathrm{D}$ & 106 & Xcfd19 & Xgdm14 & 6.6 & 2 & $99-113$ & 9.5 & \\
\hline \multirow[t]{2}{*}{5} & $7 \mathrm{~B}$ & 148 & XksuD2 & Xgwm146 & 3.7 & 0 & $130-157$ & 3.0 & $* *$ \\
\hline & & & & & & & \multicolumn{2}{|c|}{$\hat{p}_{D S}(\%)^{\mathrm{f}} \mathbf{4 5 . 5}$} & \\
\hline \multicolumn{10}{|c|}{ History/Rubens $(N=94)$} \\
\hline 1 & $4 \mathrm{D}$ & 4 & Rht-D1 & Xbarc105 & 16.6 & 0 & $0-9$ & 24.4 & $* *$ \\
\hline 2 & 5B. 1 & 34 & XwPt-4996 & Xgwm274 & 11.5 & 0 & $29-39$ & 12.0 & \\
\hline 3 & $5 B .2$ & 68 & Xbarc142 & XP7152-196 & 4.5 & 0 & $57-79$ & 11.3 & $* *$ \\
\hline 4 & $6 \mathrm{~B}$ & 16 & XP7162-180 & XР7256-485 & 7.9 & 0 & $11-21$ & 8.2 & $* *$ \\
\hline \multirow[t]{2}{*}{5} & $7 \mathrm{~B}$ & 24 & Xgwm263 & ХP6653-115 & 10.4 & 0 & $19-29$ & 7.1 & \\
\hline & & & & & & \multicolumn{4}{|c|}{$\hat{p}_{D S}(\%)^{\mathrm{f}} \mathbf{6 3 . 0}$} \\
\hline
\end{tabular}

** $F$ test significant at $P<0.01$

a Closest marker in bold

b Critical LOD scores after 1,000 permutations $(\alpha=10 \%)$ are 4.5 (Arina/Forno) and 15.8 (History/Rubens)

c $95 \%$ confidence interval after Darvasi and Soller (1997)

d Partial genotypic variance explained by detected QTL

e QTL $\times$ environment interaction tested for significance (sequentially rejective Bonferroni $F$ test)

${ }^{\mathrm{f}}$ Adjusted genotypic variance explained by detected QTL (final simultanous fit) across environments

resistances. Two BSR QTL, however, revealed resistances to STB and FHB, one to STB and SGB and another one to FHB and SGB. In History/Rubens, three BSR QTL significantly reduced both FHB and STB severity.

The LOD curves were plotted to illustrate BSR QTL in Arina/Forno (Fig. 1) and History/Rubens (Fig. 2). Effects of heading date and plant height on BSR QTL are crucial on chromosome 5B in Arina/ Forno and chromosomes 2B, 4D, and 7B in History/ Rubens, indicated by high LOD scores of these agronomic traits within support intervals of BSR QTL. In addition, significant QTL from initial QTL mapping experiments are labeled at the LOD peak. Initial QTL of Arina/Forno for STB, SGB, and FHB resistance on chromosomes $3 \mathrm{~B}, 4 \mathrm{~B}, 5 \mathrm{~B}$, and $6 \mathrm{D}$ and of History/Rubens for STB and FHB resistance on chromosomes 4D, and 7B were confirmed. Three
BSR QTL, on chromosome 5B in Arina/Forno and on chromosomes 4D and 7B in History/Rubens, are based on two initial QTL already significant in the single-trait analysis. All other BSR QTL were significant because of one detected initial QTL and the second initial QTL being below the significance level.

\section{Discussion}

The objectives of this study were to map new STB QTL and to reveal common QTL regions for BSR within two mapping populations using meta-analysis. Meta-analysis is defined as the integration of individual experiments with a comparative map-based approach. We focused on two wheat populations analyzed for quantitative resistance with different 
Table 2 Chromosomal localization, position (Pos.), flanking markers, distance to the next flanking marker (Dis.), support interval (SI), effects and donors (D) of BSR QTL for $S$. tritici blotch (STB), Fusarium head blight (FHB), and Stagonospora glume blotch (SGB) in wheat population Arina/Forno and for STB and FHB in History/Rubens $(N=$ population size)

\begin{tabular}{|c|c|c|c|c|c|c|c|c|c|c|c|c|c|}
\hline \multirow[t]{2}{*}{ Chromosome } & \multirow[t]{2}{*}{ Pos. (cM) } & \multicolumn{2}{|c|}{ Flanking marker ${ }^{\mathrm{a}}$} & \multirow{2}{*}{$\begin{array}{l}\text { Dis. } \\
(\mathrm{cM})\end{array}$} & \multirow{2}{*}{$\begin{array}{l}\text { SI } \\
(\mathrm{cM})\end{array}$} & \multirow[t]{2}{*}{ MetaLOD } & \multirow[t]{2}{*}{$P^{\mathrm{b}}$} & \multicolumn{2}{|l|}{ STB } & \multicolumn{2}{|l|}{ FHB } & \multicolumn{2}{|l|}{ SGB } \\
\hline & & Left & Right & & & & & Effect ${ }^{\mathrm{c}}$ & $D^{d}$ & Effect ${ }^{\mathrm{c}}$ & $\mathrm{D}^{\mathrm{d}}$ & Effect ${ }^{c}$ & $D^{d}$ \\
\hline \multicolumn{14}{|c|}{ Arina/Forno $(N=200)$} \\
\hline $3 B$ & 120 & Xgwm131 & Xgwm383 & 5 & $106-130$ & 6.1 & $<0.25$ & $-5.9 * *$ & A & $-3.1 * *$ & A & -0.8 & A \\
\hline $4 \mathrm{~B}$ & 16 & Xpsr914 & Xglk335 & 1 & $10-22$ & 12.0 & $<0.01$ & $-2.5 * *$ & $\mathrm{~F}$ & -0.2 & $\mathrm{~F}$ & $-2.1 * *$ & $\mathrm{~F}$ \\
\hline $5 B$ & 70 & Xgwm639 & Xpsr120 & 1 & $68-72$ & 22.7 & $<0.01$ & -1.2 & $\mathrm{~F}$ & $-3.8 * *$ & $\mathrm{~F}$ & $-1.7 * *$ & $\mathrm{~F}$ \\
\hline $6 \mathrm{D}$ & 106 & Xcfd19b & Xgdm14 & 2 & $100-110$ & 10.9 & $<0.01$ & $-3.3 * *$ & A & $-3.0 * *$ & A & -0.8 & A \\
\hline
\end{tabular}

History/Rubens $(N=94)$

\begin{tabular}{rrllllllllllllll} 
2B & 140 & XwPt-0694 & XP7056-648 & 2 & $138-144$ & 18.1 & $<0.25$ & $-3.7 * *$ & $\mathrm{R}$ & $-1.7 * *$ & $\mathrm{R}$ & - & - \\
4D & 4 & Rht-D1 & Xbarc0105 & 0 & $2-6$ & 48.7 & $<0.01$ & $-9.8^{* *}$ & $\mathrm{H}$ & $-6.3 * *$ & $\mathrm{H}$ & - & - \\
7B & 24 & Xgwm263 & XP6653-115 & 1 & $22-28$ & 30.6 & $<0.01$ & $-5.4 * *$ & $\mathrm{H}$ & $-3.1 * *$ & $\mathrm{H}$ & - & - \\
\hline
\end{tabular}

** Significant at $P<0.01$ (standard $t$ test of multiple regression)

${ }^{\text {a }}$ Closest marker in bold

b Probability of significance of the BSR QTL analyzed by critical LOD thresholds after 1,000 permutations; thresholds in Arina/ Forno are $5.76(P<0.25), 7.51(P<0.05)$, and $10.63(P<0.01)$, repectively, in History/Rubens $16.04(P<0.25), 24.62$ $(P<0.05)$, and $30.45(P<0.01)$, repectively

c Additive effects (\% leaf area affected) of BSR QTL for STB, FHB, and SGB; negative numbers reflect better resistance

${ }^{\mathrm{d}}$ Donor of resistance allele is Arina $(A)$, Forno $(F)$, History $(H)$ or Rubens $(R)$, respectively

pathogens: Arina/Forno with S. tritici, S. nodorum, F. culmorum and History/Rubens with S. tritici and F. culmorum. To our knowledge, this is the first paper in which a meta-analysis has been performed with raw data from several studies with the same progeny in adult-plant stage. The maps for the resistance combinations are, therefore, exactly the same, and this offers a good chance to detect BSR QTL by adding the LOD values using markers with similar positions. This procedure also equalizes heterogeneous error variances caused, for example, by highly differing resistance levels at different locations and/ or years. Results are more critical when comparing data from different maps or using consensus maps with only a limited number of common markers. For exactly this reason, a meta-analysis across the two populations was not possible.

For STB resistance, 5 QTL were found in each of the populations, explaining 3-24\% of genotypic variance. In total, six of them reacted differently according to the environment, thus, supporting the high proportion of genotype-environment interaction variance relative to genotypic variance (Electronic Supplementary
Material Table S1). In a previous study with two other elite winter wheat populations, a similar number of QTL was found for STB resistance (Risser et al. 2011). It can be concluded that this disease resistance in the two populations follows a typical quantitative inheritance (Electronic Supplementary Material Fig. S1) with several loci each having only a small effect. The Stb6 and Stb15 loci were not detected in our analysis because the isolates used seem to be virulent for both genes in the adult-plant stage.

On chromosome 5B, a single QTL for STB resistance was located close to Xgwm274 in Arina/Forno $\left(Q S t b . l s a \_a f-5 B\right)$ and History/Rubens (QStb.lsa_hr5B.1), indicating a QTL effective across both populations. Because of too few common markers between the two mapping populations at the respective QTL intervals, it was not possible to generate a consensus map. STB QTL in similar genomic positions to ours were previously detected on chromosomes $2 \mathrm{~B}$ and $3 \mathrm{~B}$ (Florett/Biscay), on chromosome 6B (Tuareg/Biscay), and even three QTL on chromosome 7B in Tuareg/ Biscay, History/Rubens, and Arina/Forno (Risser et al. 2011). Again, a critical comparison of these QTL for 
Fig. 1 LOD curves of BSR QTL on chromosomes 3B, $4 \mathrm{~B}, 5 \mathrm{~B}$, and 6D in Arina/ Forno for Fusarium head blight (FHB), Stagnaspora glume blotch $(S G B)$, and S. tritici blotch $(S T B)$ detected by meta-analysis; LOD curves for plant height $(P L H)$ and heading date $(H E D)$ are given for comparison; rectangles with line inside show support intervals and positions of meta-QTL; initial QTL in brackets

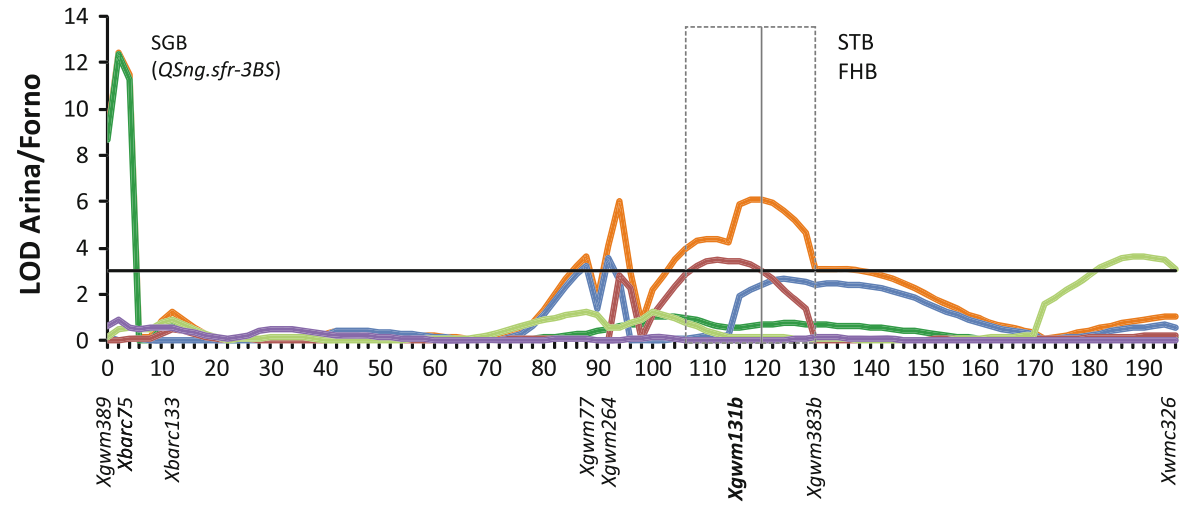

Genetic distance on chromosome (chr.) 3B in cM

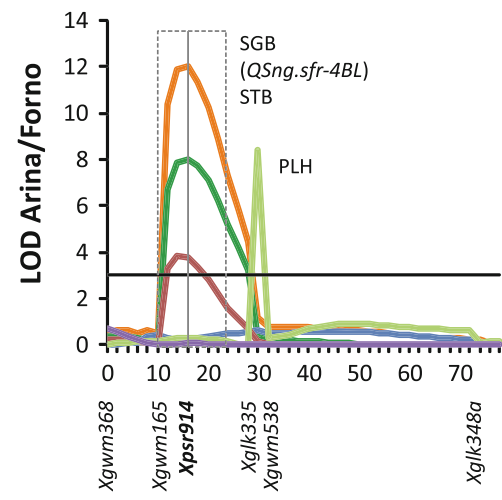

Genetic distance on chr. 4B in cM

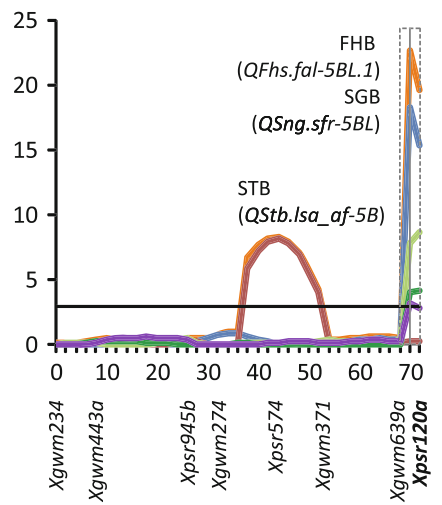

Genetic distance on chr. 5B in cM

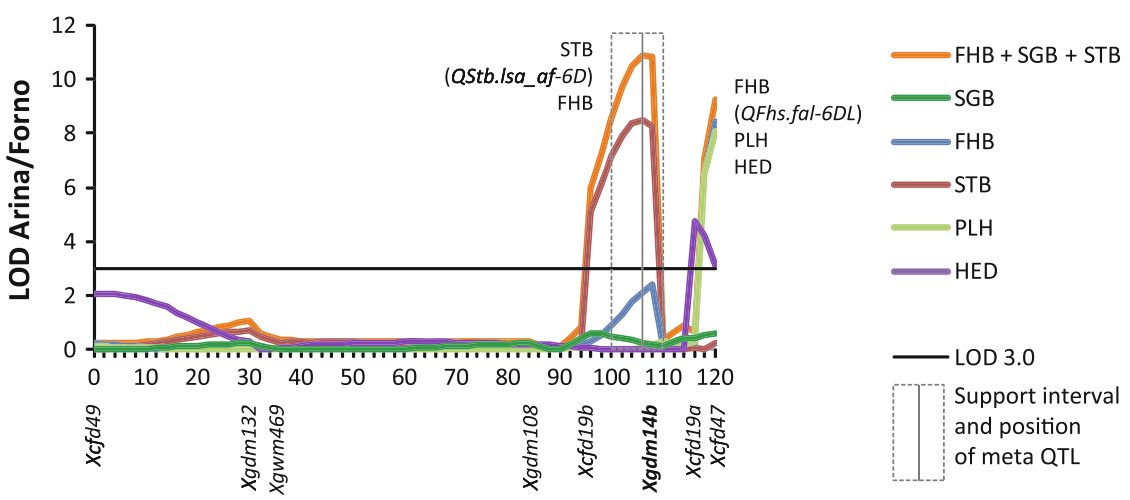

Genetic distance on chr. 6D in cM similarity was not possible due to missing common markers in the QTL regions. Eriksen et al. (2003) mapped QTL for adult-plant STB resistance in Savannah/Senat on chromosomes 2B, 3A, 6B, and 7B, altogether explaining $62-77 \%$ of phenotypic variance. SSR markers Xwmc 344 on chromosome 2B close to $Q S t b . l s a \_f b-2 B$ and $X w m c 517$ on chromosome 7B close to $Q S t b . l s a \_t b-7 B$ were, however, the only markers in accordance to the map of Savannah/Senat. Support intervals of resistance QTL did not include the common markers indicating independent QTL. Chartrain et al. (2004) detected one QTL (QStb.psr-6B-1) explaining $24 \%$ of phenotypic variance from the susceptible parent Riband in polytunnel trials at the adult-plant stage. The position of this QTL was close to SSR marker Xgwm219, which is also present in 
Fig. 2 LOD curves of BSR QTL on chromosomes 2B, 4D, and 7B in History/ Rubens for Fusarium head blight $(F H B)$ and $S$. tritici blotch $(S T B)$ detected by meta-analysis; LOD curves for plant height $(P L H)$ and heading date $(H E D)$ are given for comparison; rectangles with line inside show support intervals and positions of meta-QTL; initial QTL in brackets

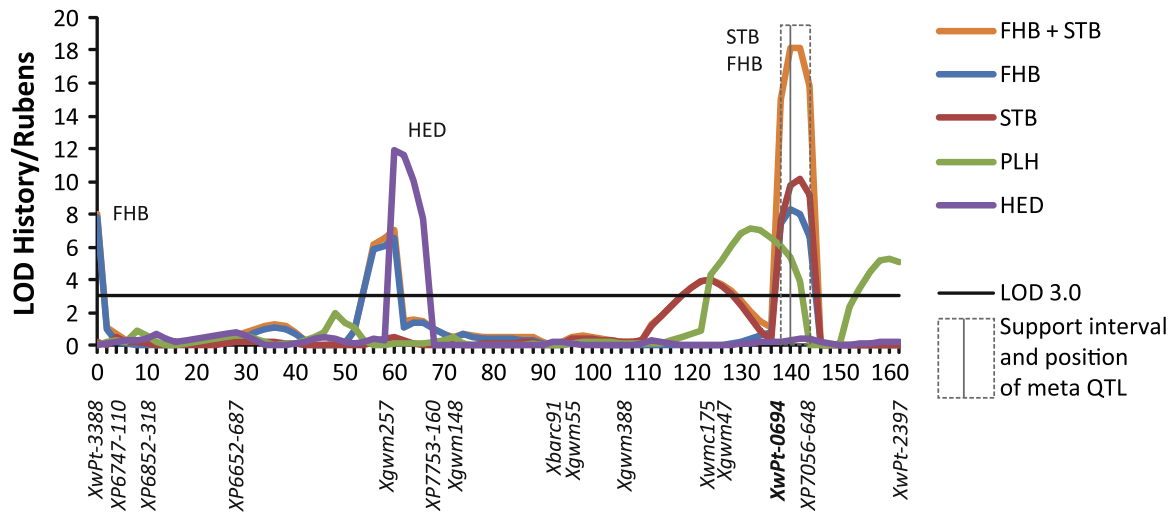

Genetic distance on chromosome (chr.) 2B in cM

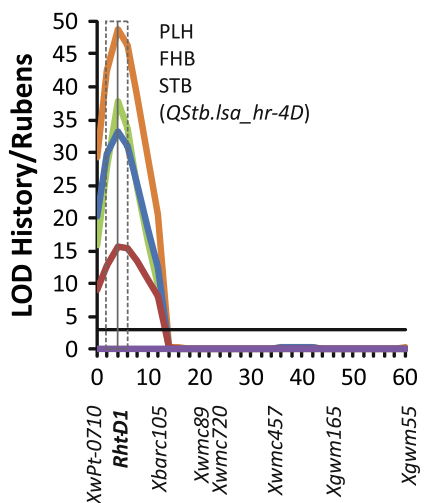

Genetic distance on chr. 4D in cM

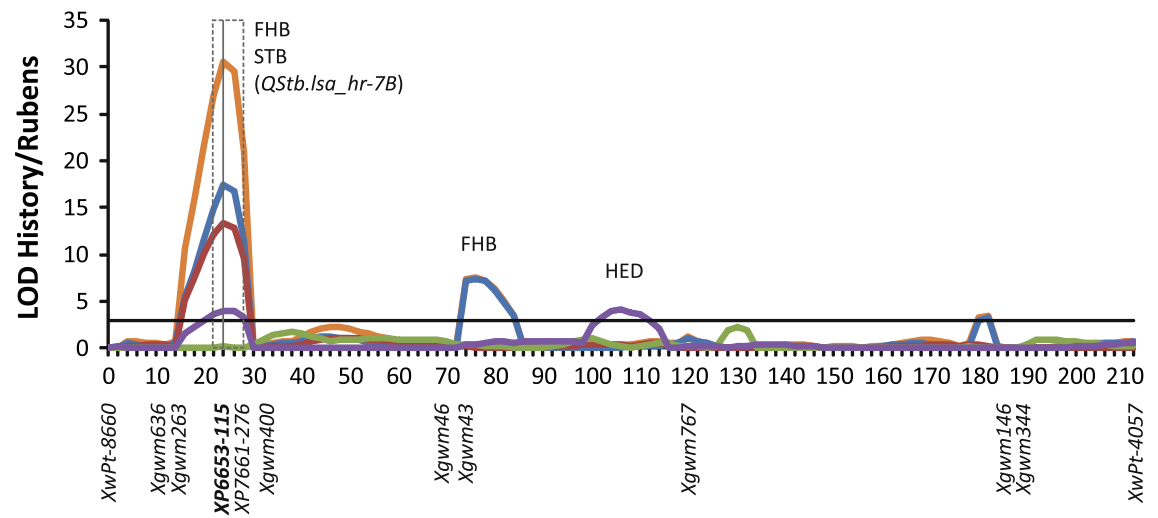

Genetic distance on chr. 7B in CM

History/Rubens, but the peak of the QTL from the present study was about $25 \mathrm{cM}$ distant from this marker. In conclusion, one and three major QTL were detected in Arina/Forno and History/Rubens, respectively, that are worth further validation for use in practical breeding.

The large effect on FHB resistance of the QTL on chromosome 4D of History/Rubens matching the dwarfing locus $R h t-D l$ has been extensively described in recent years in several populations (e.g., Voss et al. 2008; Holzapfel et al. 2008; Srinivasachary et al. 2008). A similar effect of Rht-Dl was previously detected in other wheat populations (Draeger et al. 2007; Gosman et al. 2007) and very recently retrieved by genome-wide association mapping (Miedaner et al. 2011). Until now, it was not possible to clarify whether 
the combination of tallness and FHB resistance at this locus is due to pleiotropy or linkage. In this study, we first describe an effect of Rht-Dl locus on STB resistance as being of the same magnitude as reported for FHB resistance. Of course, the locus was also detected as a meta-QTL with the tall allele causing "resistance" to both diseases. Comparing the additive effects, they were even larger for STB than for FHB resistance. This partly explains the phenotypic correlation between STB resistance and plant height in this population. Another QTL for plant height was located near the BSR QTL for STB and FHB resistances on chromosome 2B (see Fig. 2). It is, however, not recommended to use the tall allele of $R h t-D l$ in practical breeding as a resistance donor, because the resistance of this allele may simply reflect the absence of the dwarfing allele and not inherit a resistance mechanism of its own. In a study with near-isogenic lines, however, Simón et al. (2004) did not find any effect of $R h t-D l b$ from Norin 10 on STB severity. Only the extremely height-reducing genes $R h t-B l c$ and $R h t 12$ had a significant $(P<0.05)$ effect in their study. Similarly, Chartrain et al. (2004) did not find this relationship in the Arina $\times$ Riband population.

Meta-analysis by the program PLABMQTL revealed a total of 7 BSR QTL with significant additive effects for each of two diseases, with 5 BSR QTL being highly significant $(P<0.01)$ due to critical LOD scores assessed by 1,000 permutations. The highly differing critical LOD scores between the two populations are mainly due to the different population sizes. The BSR QTL on chromosome 3B (Arina/Forno) showed a peak with similar map position for each of the two disease resistances in the initial QTL analysis, but LOD values were not significant in the primary analysis and were consequently detected only at $P<0.25$ in the meta-analysis.

Four significant $(P<0.01)$ BSR QTL for different disease combinations were detected besides the RhtD1 locus: three on the B genome and one on the D genome. Initial QTL in Arina/Forno of Schnurbusch et al. (2003) for SGB and of Paillard et al. (2004) for FHB as well as in History/Rubens of Holzapfel et al. (2008) for FHB were confirmed by reanalyzing raw data with PLABMQTL. In Arina/Forno, BSR QTL were detected across each of two fungal pathogens, but not across all three pathogens. However, positive side effects of BSR QTL to the third pathogen exist, as shown for chromosome $5 \mathrm{~B}$, where $\mathrm{STB}$ infection is reduced by selecting the resistant allele effective for resistance to FHB and SGB (Table 2). Interestingly, the resistance locus Sng.sfr-3BS for $S$. nodorum resistance that is widespread in European elite winter wheat (Tommasini et al. 2007) resides in the same region as Fhbl of Asian origin for FHB resistance (Löffler et al. 2009) together with four race-specific resistances to biotrophic pathogens. In fact, there is increasing evidence for the existence of BSR QTL, because they were detected independently from the crop (e.g. Arabidopsis, maize, rice, wheat) and the pathosystem (e.g., STB, FHB, SNG, tan spot in wheat). The main question is whether this reflects just a random colocalization of resistance genes in generich genomic regions or the action of the same gene on different pathogens. Poland et al. (2009) discussed several hypotheses for explaining the potential mechanisms underlying BSR QTL. The most probable hypothesis for the pathosystems analyzed in this study is their involvement in basal defense reaction or even non-host resistance and/or defense signal transduction. Because the pathogens analyzed are not genetically related and infect different plant organs (flag leaf vs. head) in different adult-plant stages (flag leaf extension vs. flowering), the hosts' resistance reaction might be triggered by widely conserved pathogen elicitors. Molecular studies in Arabidopsis support the hypothesis that pattern-recognition receptors can condition quantitative differences in resistance to several pathogens (Miya et al. 2007; Wan et al. 2008). In future analyses, synteny relations will promote detection of BSR QTL across crops also. Head blight in wheat and ear rot in maize, both caused by $F$. graminearum, might be a promising model.

In conclusion, meta-analysis is an useful tool for detecting common regions for quantitative disease resistances, especially when based on the same maps. By using original resistance scoring data, we detected a total of 5 significant $(P<0.01)$ BSR QTL across each of two pathogens in the adult-plant stage, a fact that has not been shown before in wheat. Closely linked markers are available, and small support intervals of some BSR QTL indicate high accuracy of the meta-QTL positions. Further research is required to validate STB QTL with major effects as well as BSR QTL in different genetic backgrounds. As all three resistances are mainly affected by additive effects, the combination of major QTL in 
breeding material seems promising and breeders should concentrate on those QTL that reveal BSR.

Acknowledgments The authors would like to thank the field crews at all locations for their excellent technical assistance in data collection, in particular Bärbel Lieberherr and Manfred Buck (Universität Hohenheim), Lydia Giehl and Thomas Wirth (Institute of Crop Science and Plant Breeding, Freising), Meike Scholz (KWS LOCHOW, Wohlde). We also thank Dr. Ute Kastirr, Julius-Kühn-Institut (JKI), Quedlinburg, for sharing the isolates and highly acknowledge the determination of qualitative $S t b$ genes in our wheat parents and isolates in the lab of Dr. G.J. Kema, Wageningen UR, Plant Research International, the Netherlands. This project was financially supported by the Bundesministerium für Bildung und Forschung (BMBF, Bonn) via PTJ (Jülich) and the KWS LOCHOW GMBH within the German-French-Spanish ERANet PG-CEREHEALTH Consortium (Project no: 0313992B).

\section{References}

Abeysekara NS, Friesen TL, Keller B, Faris JD (2009) Identification and characterization of a novel host-toxin interaction in the wheat-Stagonospora nodorum pathosystem. Theor Appl Genet 120:117-126. doi:10.1007/s00 122-009-1163-6

Bonin CM, Kolb FL (2009) Resistance to Fusarium head blight and kernel damage in a winter wheat recombinant inbred line population. Crop Sci 49:1304-1312

Cao H, Li X, Dong X (1998) Generation of broad-spectrum disease resistance by overexpression of an essential regulatory gene in systemic acquired resistance. Proc Natl Acad Sci USA 95:6531-6536

Chartrain L, Brading PA, Widdowson JP, Brown JKM (2004) Partial resistance to Septoria tritici blotch (Mycosphaerella graminicola) in wheat cultivars Arina and Riband. Phytopathology 94:497-504

Churchill GA, Doerge RW (1994) Empirical threshold values for quantitative trait mapping. Genetics 138:963-971

Darvasi A, Soller M (1997) A simple method to calculate resolving power and confidence interval of QTL map location. Behav Genet 27:125-132

Draeger R, Gosman N, Steed A, Chandler E, Thomsett M, Srinivasachary, Schondelmaier J, Buerstmayr H, Lemmens M, Schmolke M, Mesterhazy A, Nicholson P (2007) Identification of QTLs for resistance to Fusarium head blight, DON accumulation and associated traits in the winter wheat variety Arina. Theor Appl Genet 115: $617-625$

Eriksen L, Borum F, Jahoor A (2003) Inheritance and localisation of resistance to Mycosphaerella graminicola causing Septoria tritici blotch and plant height in the wheat (T. aestivum L.) genome with DNA markers. Theor Appl Genet 107:515-527

FAOSTAT (2010) Food and agriculture organization of the United Nations. Production-crops. Internet resource: http://faostat.fao.org/site/567/default.aspx\#ancor (verified 18 Jan 2011)
Goffinet B, Gerber S (2000) Quantitative trait loci: a metaanalysis. Genetics 155:463-473

Goodwin SB (2007) Back to basics and beyond: increasing the level of resistance to Septoria tritici blotch in wheat. Australas Plant Pathol Soc 36:532-538

Gosman N, Bayles R, Jennings P, Kirby J, Nicholson P (2007) Evaluation and characterization of resistance to Fusarium head blight caused by F. culmorum in UK winter wheat cultivars. Plant Pathol 56:264-276

Gurung S, Bonman JM, Ali S, Patel J, Myrfield M, Mergoum M, Singh PK, Adhikari TB (2009) New and diverse sources of multiple disease resistance in wheat. Crop Sci 49:1655-1666

Holzapfel J, Voss HH, Miedaner T, Korzun V, Häberle J, Schweizer G, Mohler V, Zimmermann G, Hartl L (2008) Inheritance of resistance to Fusarium head blight in three European winter wheat populations. Theor Appl Genet 117:1119-1128

Jiang C, Zeng Z-B (1995) Multiple trait analysis of genetic mapping for quantitative trait loci. Genetics 140: 1111-1117

Knapp SJ, Stroup WW, Ross WM (1985) Exact confidence intervals for heritability on a progeny mean basis. Crop Sci 25:192-194

Krattinger SG, Lagudah ES, Spielmeyer W, Singh RP, HuertaEspino J, McFadden H, Bossolini E, Selter LL, Keller B (2009) A putative ABC transporter confers durable resistance to multiple fungal pathogens in wheat. Science 323:1360-1363

Liu S, Hall MD, Griffey CA, McKendry AL (2009) Metaanalysis of QTL associated with Fusarium head blight resistance in wheat. Crop Sci 49:1955-1968

Löffler M, Schön C, Miedaner T (2009) Revealing the genetic architecture of FHB resistance in hexaploid wheat (T. aestivum L.) by QTL meta-analysis. Mol Breed 23:473-488

Miedaner T, Löffler M, Risser P, Schweizer P, Ebmeyer E, Korzun V, Kessel B, Ouzunova M (2008) Genetische und molekulare Analyse von drei Pathosystemen bei Weizen und Mais: Fusarium and Septoria [In German]. In: 59. Tag. Vereinig. Pflanzenzüchter Saatgutkaufleute Österreichs 59:13-18

Miedaner T, Würschum T, Maurer HP, Korzun V, Ebmeyer E, Reif JC (2011) Association mapping for Fusarium head blight resistance in European soft winter wheat. Mol Breed. doi:10.1007/s11032-010-9516-z (online)

Miya A, Albert P, Shinya T, Desaki Y, Ichimura K, Shirasu K, Narusaka Y, Kawakami N, Kaku H, Shibuya N (2007) CERK1: a LysM receptor kinase, is essential for chitin elicitor signaling in Arabidopsis. Proc Natl Acad Sci USA 104:19613-19618

Paillard S, Schnurbusch T, Winzeler M, Messmer M, Sourdille P, Abderhalden O, Keller B, Schachermayr G (2003) An integrative genetic linkage map of winter wheat (T. aestivum L.). Theor Appl Genet 107:1235-1242

Paillard S, Schnurbusch T, Tiwari R, Messmer M, Winzeler M, Keller B, Schachermayr G (2004) QTL analysis of resistance to Fusarium head blight in Swiss winter wheat ( $T$. aestivum L.). Theor Appl Genet 109:323-332

Poland JA, Balint-Kurti PJ, Wisser RJ, Pratt RC, Nelson RJ (2009) Shades of gray: the world of quantitative disease resistance. Trends Plant Sci 14:21-29 
Risser P (2010) Mapping of quantitative-trait loci (QTL) for adult-plant resistance to Septoria tritici in 5 wheat populations ( $T$. aestivum L.). $\mathrm{PhD}$ thesis, University of Hohenheim, Germany, pp 1-95

Risser P, Ebmeyer E, Korzun V, Hartl L, Miedaner T (2011) Quantitative-trait loci for adult-plant resistance to Mycosphaerella graminicola in two large winter wheat populations. Phytopathology (Accepted)

Schnurbusch T, Paillard S, Fossati D, Messmer M, Schachermayr G, Winzeler M, Keller B (2003) Detection of QTLs for Stagonospora glume blotch resistance in Swiss winter wheat. Theor Appl Genet 107:1226-1234

Schön CC, Utz HF, Groh S, Truberg B, Openshaw S, Melchinger AE (2004) Quantitative trait locus mapping based on resampling in a vast maize testcross experiment and its relevance to quantitative genetics for complex traits. Genetics 167:485-498

Semagn K, Skinnes H, Bjrnstad A, Maroy AG, Tarkegne Y (2007) Quantitative trait loci controlling Fusarium head blight resistance and low deoxynivalenol content in hexaploid wheat population from Arina and NK93604. Crop Sci 47:294-303

Shankar M, Walker E, Golzar H, Loughman R, Wilson RE, Francki MG (2008) Quantitative trait loci for seedling and adult plant resistance to Septoria nodorum in wheat. Phytopathology 98:886-893

Simón MR, Worland AJ, Struik PC (2004) Influence of plant height and heading date on the expression of the resistance to Septoria tritici blotch in near isogenic lines of wheat. Crop Sci 44:2078-2085

Srinivasachary, Gosman N, Steed A, Simmonds J, Leverington-Waite M, Wang Y, Snape J, Nicholson P (2008) Susceptibility to Fusarium head blight is associated with the Rht-D1b semi-dwarfing allele in wheat. Theor Appl Genet 116:1145-1153. doi:10.1007/s00122-008-0742-2

Tommasini L, Schnurbusch T, Fossati D, Mascher F, Keller B (2007) Association mapping of Septoria nodorum blotch resistance in modern European winter wheat varieties. Theor Appl Genet 115:697-708

Uphaus J, Walker E, Shankar M, Golzar H, Loughman R, Francki M, Ohm H (2007) Quantitative trait loci identified for resistance to Stagonospora glume blotch in wheat in the USA and Australia. Crop Sci 47:1813-1822

Utz HF (2001) PLABSTAT: a computer programme for statistical analysis of plant breeding experiments. Universität Hohenheim, Institute of Plant Breeding, Seed Science, and Population Genetics

Utz HF (2009) PLABMQTL: software for meta-QTL analysis with composite interval mapping. Version $0.5 \mathrm{~s}$. Universität Hohenheim, Institute of Plant Breeding, Seed Science, and Population Genetics

van der Werf J (2000) Multiple trait models for QTL analysis In: Brian K, van der Werf J (eds) Identifying and incorporating genetic markers and major genes in animal breeding programs, pp 99-103. QTL Course: June 2000, Belo Horizonte-Brasil. Internet resource: http://www. animalgenome.org/edu/QTL/Julius_notes/ (verified 23 Mar 2011)

Voss HH, Holzapfel J, Hartl L, Korzun V, Rabenstein F, Ebmeyer E, Coester H, Kempf H, Miedaner T (2008) Effect of the Rht-D1 dwarfing locus on Fusarium head blight rating in three segregating populations of winter wheat. Plant Breed 127:333-339

Wan J, Zhang X-C, Neece D, Ramonell KM, Clough S, Kim S-Y, Stacey MG, Stacey G (2008) A LysM receptor-like kinase plays a critical role in chitin signaling and fungal resistance in Arabidopsis. Plant Cell 20:471-481

Wisser RJ (2006) The genetic architecture of disease resistance in maize: a synthesis of published studies. Phytopathology 96:120-129

Wisser RJ, Sun Q, Hulbert SH, Kresovich S, Nelson RJ (2005) Identification and characterization of regions of the rice genome associated with broad-spectrum, quantitative disease resistance. Genetics 169:2277-2293

Zhu S, Rossnagel BG, Kaeppler HF (2004) Genetic analysis of quantitative trait loci for groat protein and oil content in oat. Crop Sci 44:254-260

Zwart RS, Thompson JP, Milgate AW, Bansal UK, Williamson PM, Raman H, Bariana HS (2010) QTL mapping of multiple foliar disease and root-lesion nematode resistances in wheat. Mol Breed 26:107-124 